\title{
Motivation-Based Performance Design in Early Predicted Building Water Use
}

Tyrone Marshall

Medellin | Colombia

Perkins\&Will | United States of America | tyrone.marshall@perkinswill.com

\author{
Marcelo Bernal \\ Perkins\&Will | United States of America | marcelo.bernal@perkinswill.com
}

Eric Brossy de Dios

Perkins\&Will | United States of America | eric.brossydedios@perkinswill.com

Roya Rezaee

Perkins\&Will | United States of America | roya.rezaee@perkinswill.com

Victor Okhoya

Perkins\&Will | Canada | victor.okhoya@perkinswill.com

Nunggu Ahn

Georgia Institute of Technology | United States of America | ahn@gatech.edu

John Haymaker

Perkins\&Will | United States of America | john.haymaker@perkinswill.com

\begin{abstract}
There is a lack of impactful tools or guidance for assessing water consumption or where there can be considerable savings from water capture. While there are many online calculators, spreadsheets, and models for considering predicted building water use, none of them introduce learning through motivation in the process. Gamification has been recognized in the literature to support motivation using design elements to promote behavior change and performance to a specific activity. The authors propose the use of simple design elements within an modified building performance methodology that can drive awareness and inform the decision-making process relative to the program.
\end{abstract}

Keywords: Gamification, Motivation, Rainwater Harvesting, Water Conservation Measures, Water Use Intensity.

\section{INTRODUCTION}

Most of the tools for assessing strategies for water conservation lack a critical consideration in improving human performance in using them with feedback, flow, and learning support. The use of simple online calculators, models, and spreadsheets to assess the strategies for water conservation measures in building water use is everywhere. The tools present to the designer a set of sequences without any connection between the overall goals. The incentive to lower the proposed design water use below a baseline is just a simple byproduct of the calculation procedure. The designer has very little in the way of performance tools that consider their behavior and alignment with their goal in water conservation measures to reduce indoor water use.

How do we inspire water-conservation performance design objectives early in the design process? There have been studies in business and education to understand the use of gamification to influence human behavior, physical training, and learning opportunities (Micheel et al., 2015). Typically, behavior change in water savings usually receives attention in the context of operations, which for a building happens after it is built and then occupied. Micheel et al propose that a post-design toolset consists of dashboards focused on the motivation of consumer change in behavior through the use of visualization of water consumption through detailed data and time increments from the measurement down to the fixture and appliance level for long-term sustainable behavior changes. There has been worked to address consumer water consumption for a building after the design process. Seldom has there been a critique to focus on inspiring behavior change in the earlydesign decision process to reduce predicted water-use. The integration of goal objectives, immediate context, broader narrative, decision-making autonomy, and feedback and flow allows for the use of motivational encouragement to change behavior from the use of game design elements in early-design water-use tools.

Gamification uses game design elements in real-world scenarios for non-gaming purposes to promote and motivate human behavior and performance for a given activity (Sailer, Hense, Mandl, \& Klevers, 2013). The principle of understanding the use of gamification design elements, according to Sailer et al, is to understand the target group, the environment, and the context. Sailer et al 
state that the gamification design elements in a different context appear in approaches to airline frequent flyer offers, bonuses, and other loyalty programs. Non-gaming purposes can be when there is a desire to inspire and motivate a designer towards a clearly stated goal. Such as taking into consideration water conservation measures in the design of a building. The objective is to improve both the quality of the design, including aesthetics, envelope, systems, and interior configuration massing, and improve the performance and integration of the constituent parts in a cohesive whole. Gamification relies much more on the design process than it does on technology or hardware, which differs from the context of game entertainment and use, support, and deployment of technological devices and hardware (Sailer, Hense, Mayr, \& Mandl, 2017). Gamification uses game design elements in a non-gaming context to motivate and improve the designer's decisionmaking process in the area of building performance.

Gamification provides a set of new concepts to drive the decision-making process. The focus examines the use of game design elements' effects to realize reductions in predicted building water-use consumption. Game design elements work as devices that allow designer to understand their relationship to their behavior, consequences, performance through a system of points, badges, leaderboards, progress, avatars, and social profiles. The game design elements interact with a behavioral feedback system. The combination of elements drives the designer's understanding of their status, competence, task direction, attitude, achievement, rank, performance, progress, success, control, competition, affiliation, and membership. The psychological processes that underly the use of game design elements elevate designer's awareness and play a part in their decisionmaking process. It fosters the designer's capacity to learn and develop autonomy. As it relates to the design of a building and water-use conservation, not all of these may be necessary for use in a single context. At its core, the goal is to understand how to use gamification design elements as a psychological process effectively. It can harness the need for motivation and desire in the designer to understand their actions and how their design choices impact water consumption performance.

Tools and guidance for assessing early-design water conservation, recycling, and reuse lack sufficient designer motivation. These mostly divide the more extensive narrative into groupings of tasks through multiple screens or worksheets. The flow and feedback disconnect from the main objective or whole of the context-the work lost in the details or assumes a focus that may not be appropriate for early-design.

The authors propose the use of simple game design elements within an existing building performance model that can drive the designer's awareness and inform their decision-making process relative to consideration for the form and program. The process starts with consideration for the designer who make use of it and have an interest in designing a building that will reduce, recycle, and reuse water. The work uses gamification and its game design elements that arise from several psychological motivation perspectives that drive designer behavior and response to lower building water consumption. It provides a connected feedback system in a single overview reliant upon a clear narrative with smaller tasks to drive a point system and performance graphs. These elements help communicate, motivate, and create learning opportunities for the designer about their choices related to the building's predicted water use intensity and a proposed design performance reduction over a baseline.

Designers experience real-time feedback of changes in their form and program consideration with the implications relative to their goals for reducing water use. The authors present a workflow integration with embedded knowledge, parametric analysis, and introduce game elements with characteristics that can influence the behavior in designers to inform the decision-making process. Existing models do not specifically in their framework consider the use of elements that maintain a clear objective of the goal. Typically, these models have many intermediate and distractive elements and lack a cohesive connection to the location of the designer within the overall progression of the task. The new process merges a visual mechanism for assessing roof form, water conservation objective inputs, and outputs with a single objective and visual connection to the status at all times. The results are available from the implementation of the model to make it easy to collect and place into other platforms for distribution to another designer. The work incorporates an approach to reduce, reuse, and recycle in the context of early design to design more climate and resilient buildings that promote environmentally, economically, and socially sustainable development (Brears, 2020).

A concept map created by the authors shows the relationship of a small selection of gamification design elements and psychological motivation perspectives (Figure 1). The map shows the elements that drove the needs and requirements for a new model for introducing water conservation into the early-design process for architectural projects. The diagram provided the desired behavior change drivers and the integrated elements and framework for the work. The map introduced motivation elements from circle shapes with the thicker edges: Perspective of Emotion, Self-Determination Perspective; Perspective of Interest; Cognitive Perspective; and Behaviorist Learning Perspective. The game design elements used circles with less thick edges, such as points, performance graphs, progress bars, and meaningful stories. The circles with the thinnest edges provided the target attributes derived from the game design elements. The shaded circles relate to the features that were important to the authors, while the grey edge circles were not. For the use of the map, the authors selected the psychological motivation element. The authors then traversed the network diagram to understand the game design elements and attributes that are a consequence of it. For the water consumption model, the authors are interested in the behaviorist learning perspective as a motivational pull. The game design elements that drive behavior will be performance graphs and points. Points work with the communication of positive reinforcement to the designer. Performance graphs help the designer understand their performance from their decision-making process through the flow of the feedback system. The network diagram provided a roadmap to the deliberate use of gamification in performance design contexts related to building design.

\section{GAMIFICATION DESIGN IN WATER CONSERVATION}

In past work, Michel et al. discuss gamification design elements in visualizing water and energy consumption to make use of the feedback and social interactions from timebased fixture performance aligned with psychological perspectives. They used a small set of motivation systems 


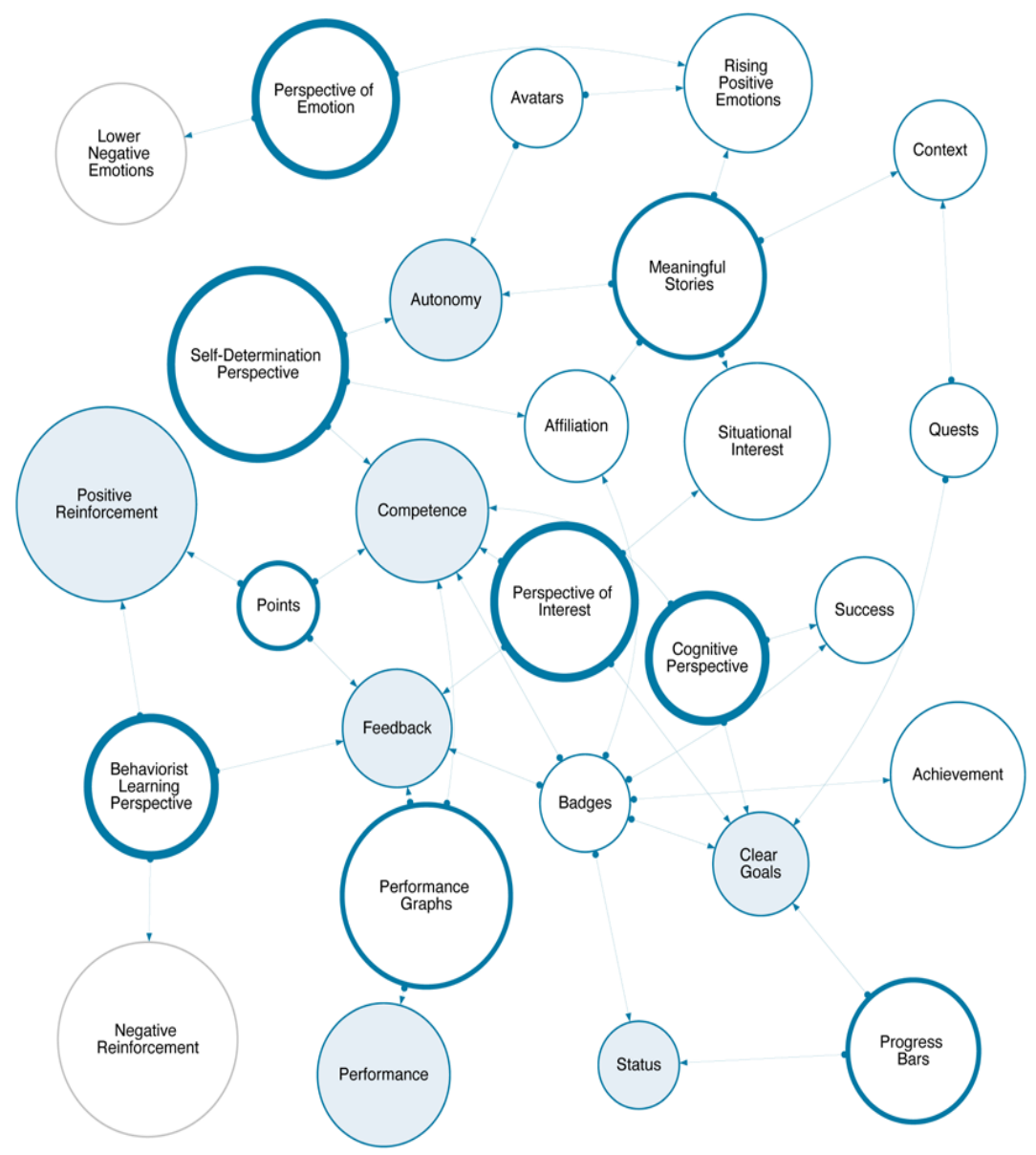

Figure 1: Gamification Motivation Perspectives and Game Design Elements Concept Map

tied to game design elements from designer interest, behavior, cognition, and perspective. The goal to reduce the building's operational water-use is a clear context and narrative for driving designers' decisions relative to the situation derived from the perspective of interest. For water consumption, Micheel et al. used progress bars and clear goals that allowed the designer to compare their behavior and receive positive or negative confirmation of their actions from the behaviorist learning perspective. Micheel et al. state that they can understand their behavior from a profile of use types such as conservative, typical, and excessive water-use. Micheel et al. point out that they can adjust their behavior for a broader framing of the status of their use from the concept of cognitive perspective through the available comparative benchmarks. The designer from a more extensive collection within a geographic context such as households or neighborhoods combined individual autonomy and group integration with values at varying scales with social relatedness. Micheel et al. have devised a context with gamification elements that work together to achieve psychological perspectives that drive learning and behavior change in operational building water and energy conservation. Still, the work from Micheel et al. do not contribute to early design consideration.

The authors focused specifically on a perspective of interest, behaviorist learning, and cognitive perspective to drive designer awareness and motivation in early-design building water consumption. Sailer et al. (2013) state that the perspective of interest provides a cognitive immersion with a dynamic and changing relationship to the designer's interaction, connection with the task, and flow from the feedback with the environmental context. The perspective of interest motivation drives the designer interest in the context from the perceived feeling of flow from their involvement, aligned with a clear objective. It must provide the capacity to advance from the consequences of applying their skill to build competence in making better performance decisions. Typically, the perspective of interest, Sailer et al. (2017) remarked that motivation derives from game design elements of a story within a larger narrative to provide a measure of autonomy and task meaningfulness. The behaviorist learning perspective 
motivation, according to Sailer et al. (2013), comprises a performance-related feedback system with positive or negative reinforcement or rewards to motivate the designer. The direct feedback allows for the fourth dimension of time through the vantage point of the designer. The designer has the advantage of memory and, if possible, can traverse many different scenario decisionmaking opportunities. The feeling of flow from the perspective of interest relates to the successful integration of the designer's behaviorist learning perspective in the context of the narrative. Sailer et al. (2013) discuss the use of points and performance graphs to change behavior through a feedback system to support the designer's understanding of their decision's outcomes in the context of their goal and its importance to their actions as a strategy to bolster competence from a more aware cognitive perspective of the situation.

\section{PAST WORK MODELS}

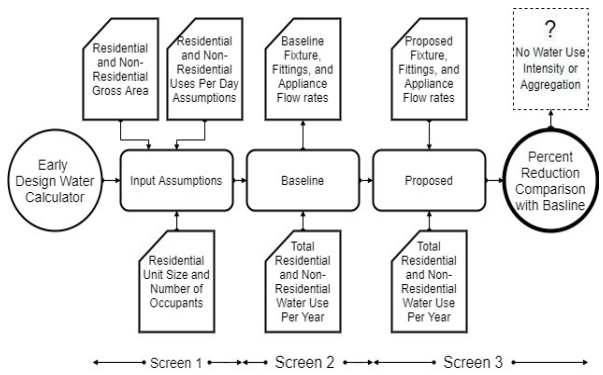

Figure 3: Green Globes Water Calculator Basic Process Diagram (A)

The authors develop and aggregate new work from existing water consumption calculators, water conservation measures, and fixture product criteria. The simple computationally driven model embeds water conservation measures, water fixture types, water usage loads, and water reuse, such as recycling and harvesting. The mechanism of a baseline and proposed case design improves the fixture flow and water use rates based on best practice water conservation measures. If the designer elected to make use of rainwater harvesting, the model calculated the number of cisterns and size based on simple math for informing the process of understanding the impact of the project configuration. In both measures, the model used game design elements such as a direction to a specific activity, the facility to motivate and change behavior when making decisions about roof design characteristics. The model featured performance indications, quick feedback, alignment to a clear objective related to water conservation and harvesting, simple task division, visual overview of the context, immersion, and autonomy in-line with the flow as a gamification set design elements. The workflow features a step by step formulation of the necessary criteria for the baseline and the proposed design project aspirations to conserve predicted building water use.

The Green Globe Water Calculator and model provides a simple method for assessing a building design for reducing predicted water consumption using a spreadsheet for assessing the certification credit in Figure 3 (Green Building Initiative, 2020). It includes both residential and non-residential uses. It also features an input for other sources such as from comfort systems, irrigation, pools, spas, fountains, and process equipment for the nonresidential program. The residential program only references comfort systems and landscape irrigation for other system sources. The calculator does not aggregate the non-residential and residential portions into single composite water consumption, nor does it calculate the water use intensity. The process requires three separate steps or worksheets to complete. The first screen allows for the standard inputs, the second has inputs for the baseline, and the third screen collects the inputs for the proposed design case. The spreadsheet features enough detail in the fixture, Fitting, and appliance flow rates, including uses per day and duration. However, the designer must have an awareness of product flow rates. They must also understand the criteria for more efficient appliances like clothes washers and dishwashers in non-residential program areas where the most significant reductions in water use. It is a simple spreadsheet-based calculator that

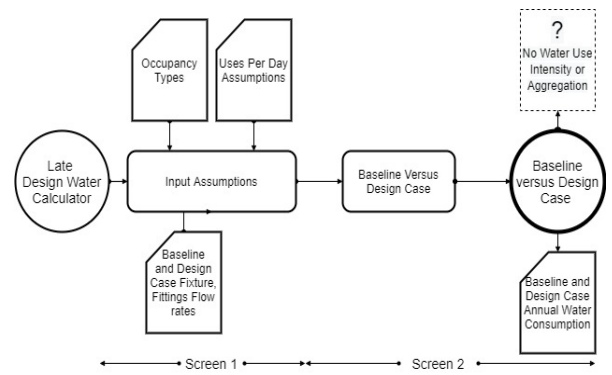

Figure 2: U.S. Green Building Council LEED V4 Indoor Water Use Calculator Basic Process Diagram (B)

provides fast feedback and allows for non-linear movement between the sets of screens to improve performance and learning.

The LEED V4.1 Indoor Water Use Reduction Calculator and model assesses a project design for the indoor water use credit certification focuses more on detail about the types of users and fixtures and fitting flow rates. Figure 2 is a simple diagram of the model that describes the primary features of the model. It does not separate or distinguishes in any way the differences between residential and nonresidential uses. The calculator focuses on indoor water use while other criteria and calculators address comfort systems and irrigation systems for outdoor water use. The calculator does not water use intensity. The process requires two separate steps or worksheets to complete. The first screen allows for the baseline and the proposed design case occupancy types, fixtures, and fitting flow rates. The last screen provides for the comparison between the baseline and the proposed design case.

Similarly, to the previous calculator, there is the detail for fixtures and fittings. However, again the designer must come prepared with product flow rates and criteria for more efficient appliances. The calculator requires an allocation for the number of employees, visitors, retail customers, students, or residents; it can be more upfront detail than necessary for early-design assessment. Again, it is a spreadsheet that has the capability to provides fast feedback and non-linear movement between the two sets of screens. 


\section{EARLY DESIGN WATER CONSERVATION AND HARVEST METHODOLOGY}

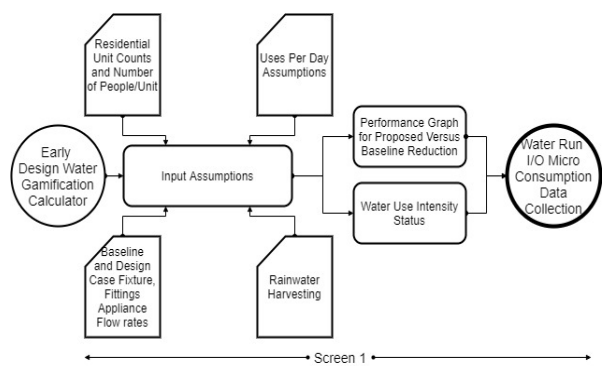

Figure 4: Early Design Water Gamification Model

The parametric early design model provides a simple method based on the Green Globe Water Calculator design for reducing predicted water consumption shown in Figure 4. The model adds many features beyond the original design. A parametric component model for the real-time model of rainwater harvesting roof surfaces and the monthly water output is collected based on a simple calculation (Texas A\&M University, 2019). It dynamically works within the Rhinoceros viewport driven parametrically by Grasshopper (Robert McNeel \& Associates, 2020). The addition of hydraulic flow indication places vector arrows along the surface normal makes it easier to understand complex roof shapes in the design of predicted shedding and the capture of water from the roof (Chen Yujiao, Samuelson, \& Tong, 2016). Almost as important as the rainwater harvesting component, the model includes cistern sizing, cistern shape, and the number of cisterns for the captured water (Young \& Sharpe, 2016). The model incorporates the assumption for greywater and blackwater treatment systems and other sources, such as the output from the rainwater harvesting model.

It includes both residential and non-residential uses. It also features an input for other sources such as comfort systems, irrigation, pools, spas, fountains, and process equipment for the non-residential program.

The early design model aggregates the non-residential and residential portions into single composite water consumption, including water use intensity. The model's left-hand side provides a detailed text-based output of all the input and output calculation summaries. The process provides all the steps in a single view with a performance graph of water use intensity in gallons/area annually. The process is a vertical stack for residential inputs, the baseline, performance bar and graphs, and the proposed design case.

All the assumptions for daily use rates and embedded steps for various fixtures, fitting, and appliance flow rates persist in the model based on actual products (Figure 5). The authors could implement the model in any other platform, such as an interactive web-based application. The model has an accompanying online database site with the recommended fixtures, flow rate, and appliance settings for various thresholds of recommended water reduction levels. The capability to incorporate the assumptions for more efficient appliances like clothes washers and dishwashers in non-residential program areas where the most significant water use reductions make the model convenient and available for other optimization processes. It is a parametric model that provides fast feedback and allows for non-linear movement in an all-at-once display for context, including performance graphs and bars, to improve performance and experience working with better outcomes for the designer.

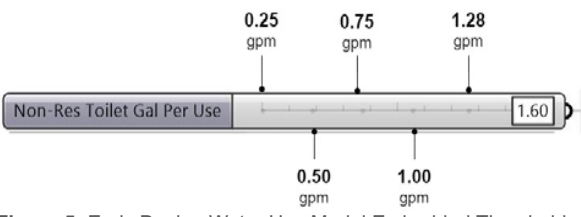

Figure 5: Early Design Water Use Model Embedded Thresholds

The authors compared the various calculator and models to understand their relationship with the gamification and motivation perspectives to pull behavior and provide learning opportunities (Table 1). All three provide an overall narrative and task description for reducing predicted indoor building water-use. The early design water gamification model $(\mathrm{C})$ adds the capability to maximize rainwater harvesting for the roof surfaces and aligns with Brear's observation of the larger narrative regarding reuse and recycling. Tools like the Green Globes Water Calculator, (A), and the U.S. Green Building Council LEED V4 Indoor Water Use Calculator, (B), assume an internal motivation and elevation of awareness in the designer. The distance of the most critical result with both calculators, including comparing the baseline to the proposed design case percent reduction, do not always keep the central focus in view at all times to the designer. Therefore, the psychological need for motivation and behavior aligns with the larger narrative regarding reuse and recycle (Brears, 2020). Tools like the Green Globes Water Calculator, (A), and the U.S. Green Building Council LEED V4 Indoor Water Use Calculator, (B), assume an internal motivation and elevation of awareness in the designer. Therefore, the psychological need for encouragement and behavior to elevate awareness do appear in the calculators. The early design gamification model, $(C)$, keeps the larger narrative always in focus. It provides thresholds for each of the interactive elements to allow the designer to change flow rates for the fixture, fittings, and appliances as smaller tasks. The view of the small details and the overall model performance helped the designer compel motivation and reduce the proposed design case indoor building water consumption with real-time always in view feedback. The motivation driver for indoor water consumption tools uses water conservation measures, which provide positive and negative reinforcement through the percent reduction indication in the tools. The separation of screens presents a challenge to task division by disrupting the sense of flow and feedback (Figure 3, Figure 2). In the two calculators, the designer only has access to the status on the last screen. As it pertains to gamification, the behavioral feedback system requires that the designer understand the relationship between their behavior and the status, performance, and progress from their consequences. Again, these are not present in the models Green Globes Water Calculator, (A), and the U.S. Green Building Council LEED V4 Indoor Water Use Calculator, (B). Neither calculator addressed the notion of all three components of 
reducing, recycle, and reuse, such as lowering water consumption, rainwater harvesting, or a grey and blackwater system. The lack of an overall context is a consequence of the task division screens in the Green Globes Water and LEED V4 Indoor Water Use calculation models. All three models allow autonomous interaction to make decisions. It is only in the early design gamification water use and harvesting model $(\mathrm{C})$ that you get embedded knowledge about the fixture, fittings, appliances, and other model components. These have been built into it to facilitate feedback systems with an always viewable performance graph to assess non-linear flow opportunities.

Table 1: Comparison of Models and Gamification Motivation and Design Elements for Green Globes Water Calculator, (A), the U.S. Green Building Council LEED V4 Indoor Water Use Calculator, (B), and the Early Design Gamification Water Use and Harvesting Model, (C).

\begin{tabular}{|c|c|c|c|c|}
\hline Element & Description & (A) & (B) & (C) \\
\hline Activity & $\begin{array}{l}\text { Reduce Water } \\
\text { Consumption }\end{array}$ & Yes & Yes & Yes \\
\hline Motivate & $\begin{array}{l}\text { Elevate } \\
\text { Awareness }\end{array}$ & No & No & Yes \\
\hline Performance & $\begin{array}{l}\text { Conservation } \\
\text { Measures }\end{array}$ & No & No & Yes \\
\hline Feedback & $\begin{array}{l}\text { Performance } \\
\text { Bars or Graphs }\end{array}$ & No & No & Yes \\
\hline Focus & $\begin{array}{l}\text { Reduce, Recycle } \\
\text { and Reuse }\end{array}$ & No & No & Yes \\
\hline Task Division & $\begin{array}{l}\text { Number of } \\
\text { Screens }\end{array}$ & 3 & 2 & 1 \\
\hline Overview & Context & No & No & Yes \\
\hline Narrative & Clear Goal & Yes & Yes & Yes \\
\hline Perspective of Interest & Immersion & No & No & Yes \\
\hline $\begin{array}{l}\text { Behaviorist Learning } \\
\text { Perspective }\end{array}$ & $\begin{array}{l}\text { Flow and } \\
\text { Feedback }\end{array}$ & No & No & Yes \\
\hline Cognitive Perspective & $\begin{array}{l}\text { Autonomy and } \\
\text { Decision Making }\end{array}$ & Yes & Yes & Yes \\
\hline
\end{tabular}

\section{RESULTS}

The indoor water (Figure 6) and rainwater harvesting (Figure 7) processes integrate the model, controls, performance bar, and graphs into a single view. The model output allows for the preparation of an easy-to-understand assessment of the water conservation measures, and monthly harvested water details. In the context of building water consumption to reduce, reuse, and recycle water in the early design of buildings, the models support parametric scenarios. A set of variable options can express different fixture flow rate options available for output and view within a parallel coordinates plot. The parallel coordinate plot provides a framework to graphically depict alternatives such as inputs for fixture flow rates as a single row connecting values to vertical columns for inputs such as toilet flush and lavatory fixture flow rates and the total water use output. The process has similarities to nonlinear decision-making and performance memory. The designer can traverse many different scenarios to impact their decision-making process. These can build a design space to complement the integration of an interface, analysis engine, software interface, and data visualization es for the generation of alternatives, impact analysis, and value assessment (Haymaker et al., 2018).

The authors propose seven sections for the early indoor water use model. Section 'A' includes measures for the number of water fixtures for all showers, toilets, diswashers, and clotheswashers. The additional measures es provide for occupancy, usage rates, and fixture flow rates. In section 'B,' we find the performance graph that compares s the baseline and proposed case water-use reduction percent and the water use intensity (Error! Reference source not found.). The model resources and controls for quick alternative generation comprise section 'C.' Section ' $D$ ' is a graphic rendition of the output from the rainwater harvesting model. Section 'E' provided an example of the resolution of the alternative options derived from the model

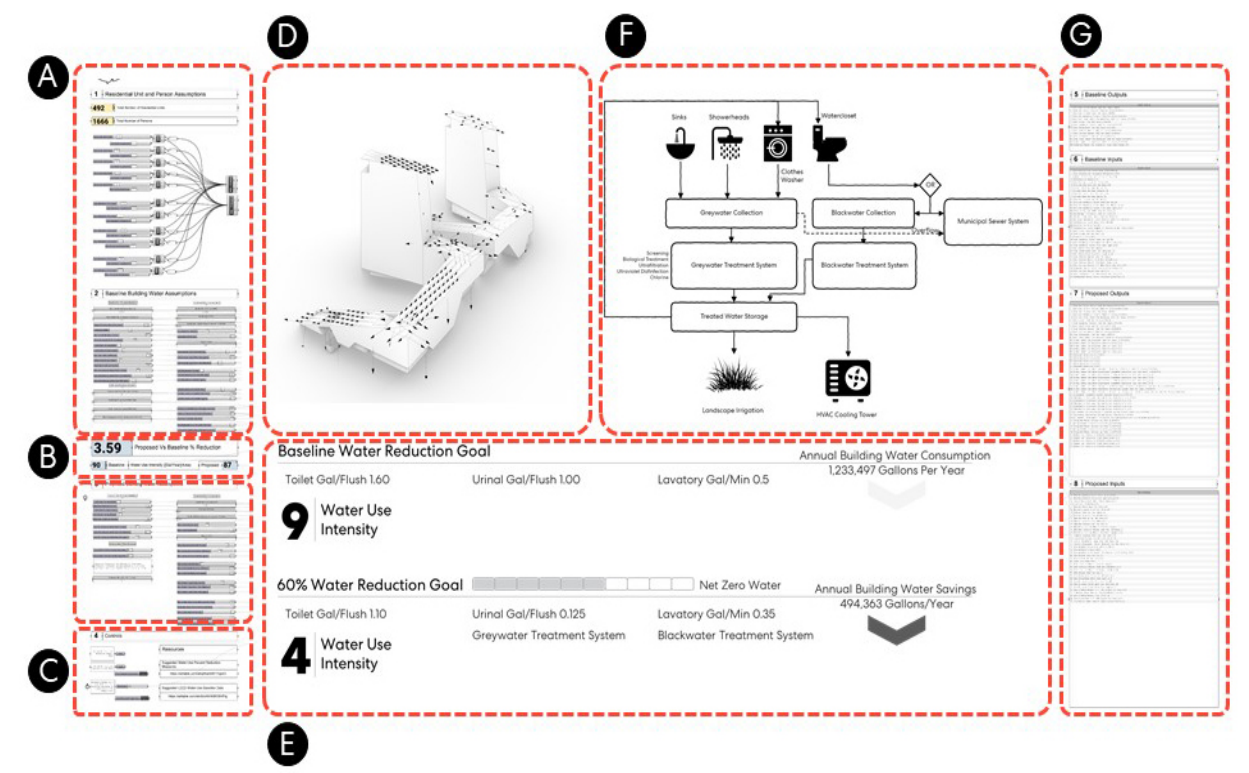

Figure 6: Indoor Water Use Gamification Model 


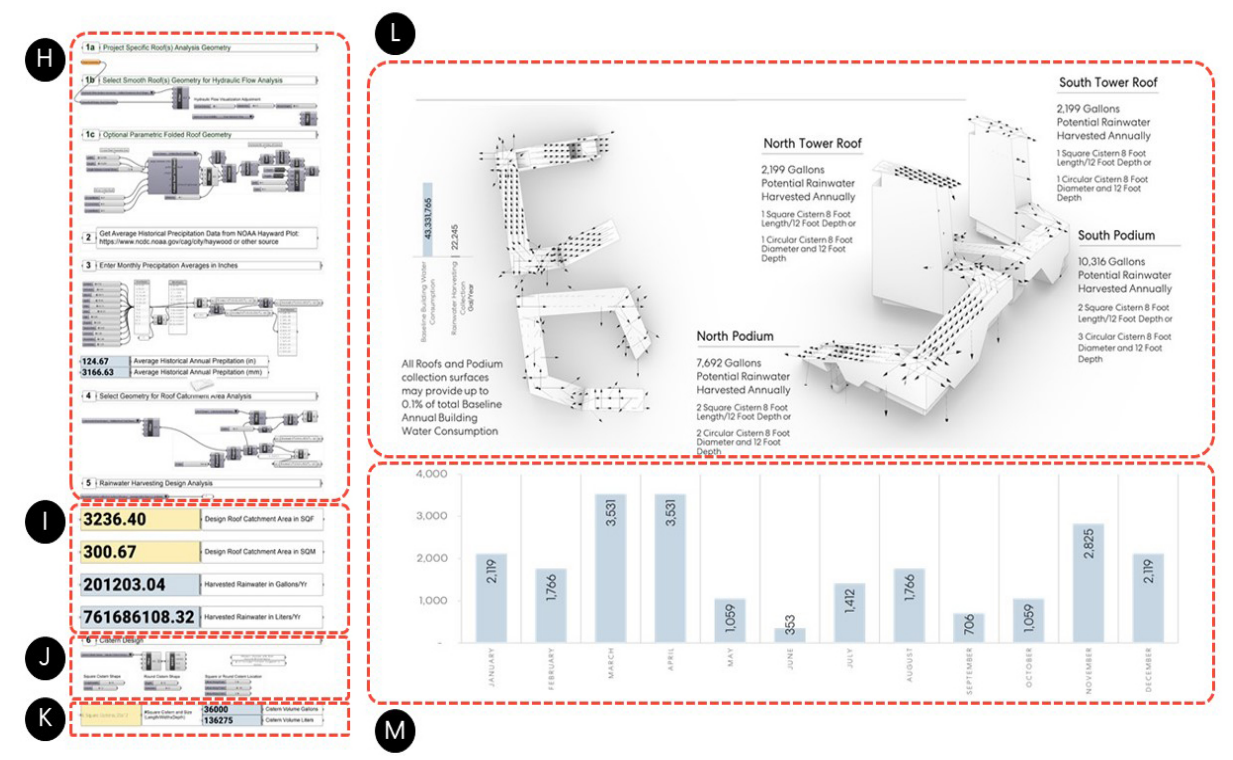

Figure 7: Early Design Rainwater Harvesting Gamification Model

output shown in section 'G.' In section 'F'; the designer can understand the assumptions for recycled water assumptions, including both grey and black water included in the model.

The rainwater harvesting model allows for a real-time computational and graphic rendition of a folded roof with variable length, width, and slope or input for custom geometry shapes to vary the length, width, and slope. Section ' $\mathrm{H}$ ' provides an interactive and fast feedback method that allows for capturing of alternatives that combine the designer's geometry design options to understand the performance potential and consequences of the storage volume in sizing cisterns for any location with historical precipitation data. The model allows location constraints for water harvesting based on monthly precipitation depth, 2D catchment surface footprint, and collection surface efficiency. The point measure and performance graph showed in section 'l' provides the roof catchment area from either the folded or custom roof option, harvested rainwater in gallons or liters per year (). The model provides the designer with a framework to consider the cistern shape and dimensions in section 'J.' A final set of real-time performance graph showed in section ' $\mathrm{K}$ ' provides the necessary predicted number of cisterns, form, and volume captured. Section 'L' and 'M' showed the actual model graphic in terms of monthly harvested volume and perspective view of the hydraulic flow, allowing the designer easy access to create visuals to explain their solution.

The models have been useful in ongoing professional projects to facilitate rapid assessment at various water reduction thresholds for $a 40,50,60$, and 70 percent water reduction. It is noteworthy to understand that the water calculation method follows with additions similar to the Green Globes Water model. It is not necessary to go into details for the paper topic. It features an accompanying sequence of decision-making choices for overall total water reduction goal, on-site greywater treatment system, consideration for the fixture, fittings, and appliances cost. The roof often has potential uses such as program, green roof, solar photovoltaics, and finally, rainwater harvesting. With so many competing performances for it, the climate conditions may be a deciding factor for which one makes the best use. The available precipitation budget becomes essential as other uses for the roof may make more sense regarding the cost versus performance for rainwater water harvesting.

The model's gamification elements provide a real-time calculation and performance graph of the roof catchment area's status from the annually harvested rainwater in a large and prominent display integrated into the model. The rainwater harvesting model's implementation uses game design elements for direct interaction and in-context with the flow of task and environment, focus, task division of each section, an overview of the goal, and performance graphs. A sub-task allowed them to design the cistern tanks for collecting the rainwater in either a square or cylinder shape. With the square shape, the designer changes the parametric control using length and depth or changing the diameter and depth to understand the harvested rainwater amounts with the round cistern. The model allows designers to visualize the cisterns' location in the Rhinoceros viewport from the grasshopper model.

Finally, they could assess the predicted harvested potential from the roof and then the cisterns' collected volume versus what they could place on the site. The model's design supports flow and feedback with a broader narrative and task sequence to maintain a clear overview of the context, such as predicted harvested capture and then collection in the cisterns. The behavior influences elements that motivate the designer to work towards a solution through the interest, behaviorist learning, and cognitive perspective 
by integrating the model within the framework to provide immediate feedback, autonomy, and sequence to aid their decision-making opportunities. The use of gamification motivation and game design elements was essential to use the rainwater harvesting model. The combination of the model and the perspective of interest, behaviorist learning perspective, and cognitive perspective work together to create a sense of immersion, immediate context, flow and feedback, and autonomy in decision-making foster learning in an educational environment. The model provides a quick, direct process for determining if it makes sense to incorporate rainwater harvesting design into the project.

\section{DISCUSSION}

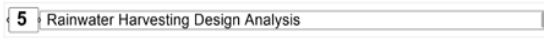

\begin{tabular}{l|l}
3236.40 & Design Roof Catchment Area in SQF \\
\hline
\end{tabular}

\subsection{7}

\subsection{4} Design Roof Catchment Area in SQM

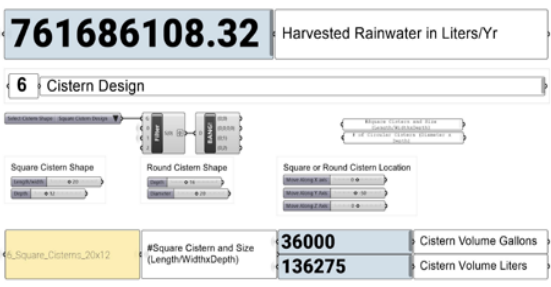

Figure 9: Water Use Intensity Point Metric and Proposed Versus Baseline Reduction Performance Graph for Early Design Water Use Model

The authors have identified designers as their group, environment, and context as early-design. The game design elements that use points and graphs with a method and implementation to change behavior for a motivation pull from the designer towards awareness and task direction for considering many strategies for reducing the predictive water-consumption in the early-design process quickly.

The authors discussed the usefulness and relevance of gamification on architectural design projects. The authors consider the limitations concerning the approach to process water, landscape irrigation, and the relationship to using the existing models that target a rating system credit. he work implements and promotes active consideration for water consumption and reuse using performance design models that motivate and enhance concerns for resilience and water use efficiency in early design. The models combine the water-use conservation measures, feedback, and visual displays into a single context in alignment with game design elements from selected psychological motivation perspectives.

In the design of an early-design building water consumption model, context is critical. A quick assessment of the building water consumption early should align with other early design objectives that focus on massing and program.
The work relates to Brear's idea that linked water conservation and a mechanism for the motivation pull to use less water to design and change behavior based on strategy, experience, and learning. The work affords a simple design, low-detail front end, and a high-level backend detail assessment characteristics of water fixtures and flow rates, rainwater harvesting, greywater, blackwater, and input process and mechanical system water use.

\subsection{Proposed Vs Baseline \% Reduction \\ 90 Baseline o Water Use Intensity ([Gal/Yeary/Area) OProposed 87}

Figure 8: Measure Point Values and Performance Graphs for Early Design Rainwater Harvesting Model

The next steps could be to deliver a selection of targeted gamification design elements and motivational perspectives down to a granular level around the design of building programs for non-residential and residential spaces and its accompanying water-use fixtures and appliances. New work may focus on automating the thresholds and settings for the fixtures, fitting, and appliance flow rates to achieve desired threshold water reduction levels. Additionally, the models can feature more gamification elements to provide other status indicators and progress bars.

\section{REFERENCES}

Brears, R. C. (2020). Developing the Circular Water Economy. In R. C. Brears (Ed.), Palgrave Studies in Climate Resilient Societies (1 ed., pp. 221). doi:10.1007/978-3-030$32575-6$

Chen Yujiao, Samuelson, H. W., \& Tong, Z. (2016). Integrated design workflow and a new tool for urban rainwater management. Journal of Environmental Management, 180, 45-51.

Green Building Initiative. (2020). Water Consumption Calculator V. 1.3. Retrieved from https://thegbi.org/training/userresources/downloads/

Haymaker, J. R., Bernal, M., Marshall, M. T., Okhoya, V., Szilasi, A., Rezaee, R., . Welle, B. R. (2018). DESIGN SPACE CONSTRUCTION: A FRAMEWORK TO SUPPORT COLLABORATIVE, PA R A M E T R I C DECISION MAKING. Journal of Information Technology in Construction, 23, 157-178.

Micheel, I., Novak, J., Fraternali, P., Baroffio, G., Castelletti, A., \& Rizzoli, A.-E. (2015). Visualizing and Gamifying Water and Energy Consumption for Behavior Change. Paper presented at the Fostering Smart Energy Applications, Bamberg, Germany.

Robert McNeel \& Associates. (2020). Rhinoceros Version 6, Seattle, WA, USA: Robert McNeel \& Associates,.

Sailer, M., Hense, J., Mandl, H., \& Klevers, M. (2013). Psychological Perspectives on Motivation through Gamification. Interaction Design and Architecture(s) Journal, 19, 28-37.

Sailer, M., Hense, J. U., Mayr, S. K., \& Mandl, H. (2017). How gamification motivates: An experimental study of the effects of specific game design elements on psychological need satisfaction. Computers in Human Behavior, 69, 371-380. doi:https://doi.org/10.1016/j.chb.2016.12.033

Texas A\&M University. (2019). Rainwater Harvesting.

Young, E. S. J., \& Sharpe, W. E. (2016). Rainwater Cisterns: Design, Construction, and Treatment. 